\title{
O papel dos Conselhos Pedagógicos na formação de professores
}

\author{
MANUEL JACINTO SARMENTO*
}

\section{INTRODUÇ̃̃O}

A formação de professores dos ensinos preparatório e secundário conheceu vários desenvolvimentos ao longo dos 12 anos posteriores d revolução. Podemos balizar com quatro marcos essa evolução: 1974/80 - estágio clássico, realizado em escolas dotadas de Centros de Estágio, dependente do Ministério da Educação e dos organismos centralizados deste; $1980 / 86$ - profissionalização $\mathrm{em}$ exercício, centrado na consecuçäo de um plano individual dos formandos, tendo os Conselhos Pedagógicos funções de orientação e avaliação e as estruturas do Ministério da Educação um papel de tutela e de apoio; 1986 - formação em serviço, dependente de instituiçôes do ensino superior dotadas de departamentos de ciencias da educação, designadamente dos centros integrados de formação de professores (CIFOP's) e das Escolas Superiores de Educação (ESE's); em todo o período considerado, o ramo educacional das Faculdades de Ciências $e$ os bacharelatos e, em substituição destes a partir de 1978, as licenciaturas em ensino das Universidades Novas $\left({ }^{1}\right)$.

* Acompanhante da Prática Pedagógica CIPOF - Universidade do Minho

(1) Ver Almeida (1981), Formosinho (1986), Freitas (1983) e Loureiro (1981). Sobre a gestāo democrática, ver Fernandes (1985).
A «gestão democrática» acompanhou, pelas atribuiçóes que foram sucessivamente cometidas aos seus órgãos-e, em particular, aos Conselhos Pedagb́gicos (a parlir daqui serão designados pelas iniciais C.P.) - as mudanças que se verificaram nos modelos de formaçao de professores. Assim, a institucionalização da profissionalização $\mathrm{em}$ exercício provocou a revogaçâo do primeiro Regulamento de Funcionamento dos Conselhos Pedagógicos (Portaria 679/77, de 8 de Novembro) tendo sido substituido por um novo Regulamento (Portaria 970/80 de 12 de Novembro), o qual, por sua vez, foi revogado como consequência da entrada em funcionamento do novo modelo da formação em serviço, passando a vigorar o Regulamento actual (Decreto-Lei 211-B/86, de 31 de Julho).

Deste fucto é lícilo extrair, desde já, duas conclusões: primeira - a formação de professores assume particular relevância na definiçâo das atribuiçôes e no funcionamento dos órgãos de gestão pedagbigica, sobretudo no C.P., dado que as únicas alterações legislativas relevantes que se operaram decorreram explícita e directamente da mudança do modelos de formação; segunda - não há uma política estável e coerente na definição das atribuições dos órgãos de gestão no que respeita à formação de professores, que consagre o seu papel autónomo nesta matéria. Por outras palavras, a gestão pedagógica das escolas não condiciona o tipo de formação de docentes mas a formação conduz a alteraçōes na gestão pedagógica. 


\section{O GRAU ZERO $\left(^{2}\right)$}

$O$ diploma que atribui forma legal aos órgãos de gestão democrática (Decreto-Lei 769-A/76, de 23 de Outubro) define as incumbências do Conselho Pedagógico como de «orientaçâa pedagógica do estabelecimento de ensino, promovendo a cooperação entre todos os membros da escola de modo a garantir adequado nivel de ensino $e$ conveniente formaçāo dos alunos» (art. 24). Pareceria deduzivel da expressāo "garantir adequado nivel de ensino» a condução de um conjunto articulado de acçōes que favorecesse a formação contínua dos professores. Também a expressão "promovendo a cooperação de todos os membros da escola» poderia pressupor açōes de enquadramento e de apoio aos docentes que aí realizassem a sua formação no âmbito dos estágios clássicos. Todavia, o primeiro Regulamento de Funcionamento dos Conselhos Pedagógicos (a partir de agora este tipo de diploma sera designado pelas iniciais R.F.C.P.), que torna explicitas as atribuiçôes o funcionamento deste tipo de b́rgão, limita e reduz drasticamente as deduçôes que o artigo acima citado parecia legitimar.

Podemos sintetizar em seis funçôes as atribuiל̧öes que o primeiro R.F.C.P. determina aos C.Ps:

1․ Função de interpretação e divulgação das instruçöes e normas dos serviços centrais;

$2^{\circ}$. Funçōes de apoio ao Conselho Directivo na planificação, preparação e organização do ano escolar, na revisão do regulamento interno da escola, na elaboração do projecto de orçamento e noutros assuntos que the sejam remetidos;

3․ Funçâo de supervisão e apetrechamento de equipamenio didáctico;

$4^{\circ}$. Função de dinamização de actividades pedagógicas, designadamente na inserção da escola no meio social, na coordenaçāo interdisciplinar, na definição de critérios de avaliação, na realização de actividades para-escolares e na sugestäo para a criação de novos cursos;

$5^{\circ}$. Função de apoio aos alunos, designadamente os inadaptados;

$6^{0}$. Função de actuação disciplinar (Ponto 3.1.).

(2) Tomamos de empréstimo esta expressão às ciências da linguagem para descrever o estado de neutralização dc capacidades e competências. Por oposição, grau ómega descreve o estado de saturação dessas competências e capacidades.
A intervenção do C.P. na formação contínua dos docentes da escola reduz-se a «propor a realização no estabelecimento de acçóes de actualização e de aperfeiçoamento dos docentes, para renovação de métodos e técnicas de ensino» (3.1.10.). $O$ diploma não refere a entidade a quem o C.P. pode propor a realizaçäo desse tipo de aç̧óes, mas o entendimento que a generalidade das escolas teve foi o de que essa entidade seria a respectiva Direcção-Geral de Ensino que, por sua vez, se encarregaria ou não de organizar as acçōes solicitadas. Em contrapartida, são cometidas aos delegados de grupo as tarefas de orientação e coordenação da aç̧ão pedagógica de todos os professores do mesmo grupo, apoiados no órgão que dirigem: o Conselho de Grupo. Também näo é competência do C.P., enquanto órgão colegial, mas dos seus membros docentes individualmente considerados, o fomento $e$ orientação das «relações escola-centro de estágio, nos estabelecimentos onde este funcione».

Em suma, a formação contínua dos professores não compete ao C.P., que se limita a propor acções a desencadear, presume-se, pela Direcção-Geral de Ensino respectiva, como não é sua atribuição o desempenho de qualquer papel na formação de novos docentes, designadamente os que carecem de complemento de formação.

Estamos no grau zero das responsabilidades $e$ competências dos C.P. na formaçẫo de professores.

\section{O GRAU OMEGA}

A implementação do novo modelo que se veio a designar por profissionalização em exercício, alterou profundamente as atribuições dos C.P.s. Estes orgãos passam agora a ser os principais responsáveis pela formação de docentes, competindo-lhes elaborar o plano de formaçăo, promover e realizar actividades conducentes a essa formaçäo, orientar e avaliar os formandos. Nunca os C.P.s contiveram tantos poderes: estamos no grau ómega das suas competências em formação.

O diploma que instituiu a profissionalização $\mathrm{em}$ exercício (Dec.-Lei 519/T1-79, de 29 de Dezembro) determina que a «observaçâo e prática pedagógicas serão orientadas pelos conselhos pedagógicos, apoiados por equipas de orientadores pedagógi- 
cos», e, mais explicitamente, que "a nivel local ( $a$ coordenação da profissionalização) caberá aos conselhos pedagógicos». Este diploma teve como consequência uma alteração na composição do C.P.: pela primeira vez têm aí assento os orientadores dos estagios dos ramos educacionais das Faculdades de Ciências e das licenciaturas em ensino das Universidades Novas, e, ainda que sem direito a voto e facultativamente, os próprios formandos (Dec.-Lei 376180, de 12 de Setembro, art. 22).

O novo R.F.C.P., também pela primeira vez, claramente articula de forma autónoma as funçôes de formação que competem a este órgão: «1-Elaborar o plano de formação de todos os docentes (...); 2Definir o tipo de apoio e acompanhamento a prestar aos professores menos experientes; 3-Coordenar a profissionalizaçâo em exercício (...); 4-Assegurar às direç̧ōes-gerais (...) a colaboração indispensável à actualização permanente do inventário das necessidades de formaçäo, bem como à respectiva avaliação» (ponto 4).

Estas competências sẫo mais detalhadamente explicitadas, no que respeita à profissionalização em exercício, por novo diploma (Portaria 64/81, de 16 de Janeiro) que as distribui por sete pontos: «1 - Programar as actividades de formação dos docentes da escola, nomeadamente as que visem os objectivos das áreas de 'sistema educativo' e 'escola' no âmbito de um plano de formação (...); 2 Orientar e coordenar as actividades de profissionalização (...); 3 - Acompanhar as actividades dos professores em profissionalização, avaliando a sua intervençäo na vida da escola; 4-Colaborar com os conselhos pedagógicos da zona, nomeadamente na racionalização do aproveitamento dos recursos disponíveis; 5 - Apoiar a elaboração do plano individual de trabalho dos professores em profissionalização na escola e acompanhar a execução do referido plano; 6 - Intervir na avaliação dos professores em profissionalizaçẫo (...); $7-$ Criar (...) uma secçẫo à qual sejam cometidas funções de planificação, acompanhamento e avaliação no âmbito das aç̧ōes de formação promovidas pela escola» (ponto 9).

Estamos, como vimos, nos antípodas das competências dos antigos C.P.s. De 8 passamos para 80 . Todavia, há uma linha de continuidade que importa aqui referir: a partir de 76 é atribuído aos delegados $e$ aos conselhos de grupo a orientação dos professores da disciplina, num apelo oblíquo a um esforço de auto-formaçāo contínua pelo confronto com as nessecidades da prática quotidiana; em 80 consagra-se esta perspectiva empiricista de formação $\left({ }^{3}\right)$.

A profissionalização é entendida como a intervenção activa e inovadora na dinâmica pedagogica da escola, sob a supervisão do delegado e do C.P., e com o contributo de organismos dependentes da direcçâa-geral de ensino respectiva. Compete ao formando, por sua vez, elaborar o diagnóstico das suas necessidades de formação e a respectiva terapêtica num plano individual de trabalho, e procurar, pela integração na vida da escola e a transformação dos seus hábitos e processos de ensino, aprender a ser professor.

Não é aqui lugar para uma crítica a este modelo de formação ( $\left.{ }^{4}\right)$. Importa notar, tão somente, que as suas contradiçóes se vieram a traduzir em três niveis de desenvolvimento: $1^{\circ}-a$ dinamização $e$ inovação pedagógicas das escolas assentaram numa hipervalorização da prática, sem um suporte teórico consistente - a fragilidade dos seus resultados traduziu-se em experiências de continuidade mal assegurada e cuja avaliação ficou por fazer $\left({ }^{5}\right)$; 2 - os C.P., dispondo "à mão» de um conjunto de professores cuja intervenção na vida da escola era vital para assegurar o seu futuro profissional, deixaram de ser o motor da escola, exercendo muitas vezes apenas funçōes de supervisão avaliadora (por exemplo, o plano de formação da escola em inúmeros casos passou a ser elaborado pelos formandos que o submeteram à aprovação do C.P.); $3^{2}$ - as seç̧ões de formação do C.P. (conhecidas nas escolas por secçöes nove-sete, tal era o ponto da portaria que as criou) substituiram, em alguns casos com alivio dos professores, as tarefas que competiam ao conjunto do órgäo-dados que possuimos indicam que, num número relevante de escolas, pelo menos um terço dos membros do C.P. se abstiveram na avaliação dos formandos que tinham a cargo, invocando insuficiente conhecimento das suas actividades.

(3) Ver Formosinho (1985).

(4) Ver Formosinho (1985 e 1986) e Freitas (1983)

(s) «É sabido que o êxito de qualquer inovaçâo depende da sensibilização dos que nela vão participar, geradora de entusiasmo: na profissionalização em exercício pode dizer-se que tudo começou sem ter sido feito um mínimo para informar e muito menos para forman - Freitas (1983), pág. 42. 
A experiência do excesso de competências e atribuiçóes dos C.P. na formação de professores funcionou como um fardo suficientemente pesado para impedir o exercício pleno dessas atribuiçōes e competências.

Entretanto, a formaçāo contínua dos professores ficou dependente das actividades, tantas vezes ritualizadas, da profissionalização em exercício ( $\left.{ }^{6}\right)$.

\section{O PONTO DA ENCRUZILHADA}

O R.F.C.F. actualmente em vigor surge em relação directa com a implementação do novo modelo de formação de professores, designado por förmaçāo em serviço. Contrariamente ao modelo anterior, que fazia depender a formação da escola $e$ da direç̧âo-geral de ensino respectiva, a formaçäo em serviço propöe a intervenção, nos vários domínios da concepção, planificação, orientação $e$ avaliação, dos centros integrados de formaçāo de professores e das escolas superiores de educação. Säo as seguintes, sumariamente, as principais inovaçóes do modelo, para aquilo que nos interessa analisar: $1^{\circ}$ - introdução de uma componente de Ciências de Educação, a ministrar em sessões presenciais pelos CIFOP's e ESE's; $2^{\circ}$ - formaçäo dos acompanhantes da prática pedagógica, sendo essa formaçâo igualmente da responsabilidade daquelas instituiçôes do ensino superior, bem como o seu recrutamento e a orientação do seu trabalho; $3^{2}$ - as escolas participam na avaliação dos formandos exclusivamente através de um professor efectivo que lhes compete designar e que integrara o júri de uma prova final, cujo resultado pesa um terço na classificação final do formando. Os CIFOP's e as ESE's podem celebrar protocolos com as escolas para intervirem na formaçäo contínua dos docentes $e$ as direç̧ôes-gerais exercem funçôes administrativas (colocação de professores e distribuição dos horários) e estão representadas no órgão de coordenação global do processo - conselho consultivo.

( $)$ «Dcu-se até uma centa inversāo de papćis - os que nccessitavam de formação passaram a ser do facto formadores du nível da sua escola, promovendo acções de formação e executando trabalhos pedagógicos» - Formosinho (1985)
Este modelo de formação coloca os C.P.s numa situação em que se confrontam com duas orientaçôes de sinal contrário: a primeira é a tradição formal de intervenção e controlo da formação de professores, por influência da prática anterior; a segunda é a efectiva redução de atribuições e poderes em consequência de o novo modelo outorgar as instituiçöes do ensino superior vocacionadas para o efeito o papel determinante.

$O$ novo R.F.C.P. acentua esta encruzilhada. Os C.P.s mantêm toda a estrutura anterior, como vimos adaptada para o desempenho de uma função: formar e avaliar professores. Estão, todavia, desprovidos dessa função.

São atribuiçôes do C.P., segundo o novo regulamento: «1 - Analisar, discutir e aprovar o plano de formação dos docentes (...); 2-Assegurar que a formaçăo dos docentes da escola seja uma formação permanente (...); 3-Colaborar com a direç̧ão-geral respectiva na inventariação de carências de formação (...);4-Definir o tipo de apoio e acompanhamento a prestar aos professores menos experientes (...); 5 -Promover formas de intercâmbiv com us conselhos pedagogicos da região ou distrito numa perspectiva de formação contínua; 6-Fazer a avaliação do processo de formação dos docentes da escola; 7-Apoiar a profissionalização $\mathrm{cm}$ exercício (SIC) de acordo com as indicaçōes da direç̧äo-geral respectiva e no âmbito da lcgislação aplicável; 8-Designar os professores que integrarão os júris de avaliação dos docentes que se encontram na profissionalização em exercício" (ponto 5 ).

Os C.P.s disporão de uma secção de formação, consituida pelo presidente do C.P., pelos delegados de grupo ou disciplina "cm que haja professores a realizar a formação em serviço», pelos orientadores dos estádios dos ramos educacionais $e$ das licenciaturas em ensino, e pelos «professores designados para fazerem parte dos júris de avaliação dos formandos na situação de profissionalização em exercício» (ponto 26). As competências da seç̧āo de formação são as de apresentar a proposta dos «projectos de formação de professores», apoiar aç̧öes de formação promovidas pelas direcçôes-gerais, acompanhar projectos educativos $e$ de investigação pedagógica de âmbito regional e local, promover a «interligação e mútun enriquecimento entre o plano de formação dos professores da escola e o plano de formação dos professores que estejam 
a realizar a sua formaçäo em serviço» e contribuir para avaliar o processo de formaçāo (ponto 28).

Detenhamo-nos em dois aspectos relevantes deste R.F.C.P.. Primeiro: a invocação das direç̧ôesgerais para tarefas de formação. Se, como vimos, essas competências não lhes assistem no modelo de formaçäo em serviço, senão nos limites referidos, é legúlimo entendê-las como competências específicas na formação contínua de professores. Todavia, a ausência de qualquer referência aos CIFOP's è̀s ESE's e, em contrapartida, o envolvimento com aquelas instituições dos professores da escola intervenientes na formação em serviço (sejam os júris da prova final, sejam os próprios formandos), coloca os C.P.s na dívida sobre quem é o seu interlocutor nesse formação. O R.F.C.P. parece desenhar um sistema de comunicação trifásico: a escola comunica com a direcção-geral, que, por sua vez, comunica com a instituição de formação. Esta perspectiva centralizadora tem óbvios inconvenientes e leva a grandes distorçöes: burocratiza aquilo que poderia ser resolvido pelo contacto directo $e$ esvazia o C.P. de qualquer papel mediador na relação da escola com o centro de formação. $O$ R.F.C.P. aponta para uma formação bicéfala: uma das suas cabeças está no C.P., dependente das interpretaçōes das direç̧ōes-gerais, e a outra, fora da escola, nos CIFOP's e ESE's, ainda que com evidentes intervençôes no quotidiano escolar, pelo acompanhamento da prática pedagógica. Por outro lado, vê-se mal como pode a formação contínua realizar-se em divórcio com a formacão em serviço (7); aquela só pode ser eficaz com a intervençäo predominante das instituiçốes do ensino superior vocacionadas para o efeito, como o reconhece a Lei de Bases do Sistema Educativo (Lei 46/86, de 14 de Outubro, art. $\left.35^{\circ}\right)$. Os instrumentos de integração entre a formação em serviço e a formação contínua, por um lado, e as escolas preparatóriase secundárias e as instituiçôes do ensino superior de formação de professores, por outro, são os protocolos a celebrar entre esses dois tipos de estabelecimentos de ensino, conforme prevê o diploma legal que regulamenta a formação em serviço (Decreto-Lei 405/86, de 5 de Dezembro, art. 4º).

Segundo aspecto relevante do actual R.F.C.P.: a confusão terminológica, de que demos conta ao sublinhar as expressões profissionalização em exer-

(') Ver Freilas (1983), pág. 44. cício $e$ formação em serviço que aparecem indiferentemente (e não podem ser consideradas sinónimas, dado corresponderem a realidades institucionais distintas), mais do que o reflexo de uma situação de transição entre dois modelos (há, com efeito, professores que desistiram, ou prolongaram por um ano, por motivos de saúde, a profissionalizaçäo em exercício e se inseriram numa situação transitória), éo espelho da indecisão que resulta da inexistência de uma perspectiva estavel do papel dos C.P.s na formaşão e os coloca na convergência de diferentes orientaçōes, que o R.F.C.P. nāo pôde dilucidar $\left({ }^{8}\right)$.

\section{CONCLUSÃO}

$O$ pintor holandês $M$. C. Escher, explorando a subtil semelhança de formas diferenciadas $e$ investindo no imaginário paradoxal das metamorfoses, pintou um quadro onde, sob um fundo alternado de preto e de branco, figuras de peixe se vão, quase imperceptivelmente, transformando em pássaros. Há um ponto, no centro desse quadro, onde a convergência das formas inicial e final configura um espaço indeciso no qual náo podemos ver já o peixe nem adivinhar ainda o pássaro. $O$ actual R.F.C.P. corporiza o centro das metamorfoses nas funçöes dos C.P.s quanto à formação de professores. Como todo o espaço de contornos indecisos, instala a perplexidade e a dúvida: afinal, que papel devem os C.P.s desempenhar na formação?

A resposta a esta questão não pode deixar de passar por uma constataçäo óbvia: a gestão pedagógica não é a mesma coisa que a ação pedagógira. O C.P., por exemplo, não pode instruir, mas contribuir para que a instrução se realize com su-

(') É ainda ccdo para verificar de que modo os C.P.s se adaplaram à nova situação. Dados por nós recolhidos (em Dezembro de 1986) em scis escolas do distrito de Braga (com e sem formação $\mathrm{cm}$ serviço, de zonas urbanas c rurais) revclaram o seguinte: três delas ainda não tinham aprovado o plano de formaçāo, as oulras três tinham aprovado um plano de actividades consagradas pela tradição da escola (comcmoraçôes, festas, semanas culturais, etc.) e difcrido para outra oportunidade a aprovaçāo de um plano de formação dos seus docentes. Abre-se, assim, um campo para futuras investigações, capazes de darem conta das alterações sofridas no quotidiano das escolas, das (novas?) atitudes tomadas pelos C.P.s perante a formaçũo $c$ da particjpaçāo dos formandos no conjunto das actividades programadas. 
cesso. O C.P. näo pode formar, mas deve contribuir para o sucesso da formação dos professores que trabalham na escola. A formação de professores é uma tarefa complexa onde importa articular muitas variaveis: a teoria com a prática, numa perspectiva de teorização da prática e de prática da teoria; a intervenção quotidiana dos professores com a investigaçâo das ciências da educação; as realidades locais e regionais com o perfil do professor actual, capaz de se adaptar a diferentes condiçóes de trabalho; as escolas com os centros de formaçäo. Por outro lado, as necessidades de formação são diferenciadas: há professores sem habilitação própria que carecem de complemento de formação; há professores que têm formação inicial na componente académica da especialidade mas carecem dela em ciências da educação; há professores profissionalizados que carecem de formaçao continua. Atentemos nos professores que estão no segundo caso: o facto de realizarem a sua formação em serviço, e não por via institucional, não invalida que ela seja uma formação inicial em ciências da educação ( $\left(^{9}\right)$. Ora, esta é claramente da competência autónoma das instituiçōes do ensino superior vocacionudas para o efeito, e não das escolas onde esses professores exercem a sua actividade.

O C.P. tem, neste quadro, um papel a desempenhar: articular as necessidades locais com a oferta da intervenção formativa das instituiçöes do ensino superior. O seu papel é particularmente relevante no apoio aos professores com necessidades de complemento de formação bem como de formação contínua dos professores profissionalizados. Não lhe compete ser o principal agente formador; tão pouco abandonar competências próprias do seu âmbito de artuação, nem situar-se na zona obscura das indefiniçôes - compete-lhe contribuir para integrar a formação de professores no plano mais geral do desenvolvimento educativo e comunitário.

\section{BIBLIOGRAFIA CITADA}

ALMEIDA, E.P. (1981) - Formaçăo de professores, in M. Silva e I. Tamén (coordenadores), O Sistema de Ensino em Portugual, Lisboa, Fundação C. Gulbenkian, 1981

(9) Ver Formosinho (1985)
FERNANDES, ANTÓNIO SOUSA - A gestão democrática das escolas - notas sobre a experiência das escolas secundárias portuguesas após a Revolução do 25 de Abril, in O Ensino, Revista Galaico-Portuguesa de Sócio-Pedagogia e Sócio-Linguística, $n^{\circ}$ s 11 $12-13,1985$

FORMOSINHO, JOÄO (1985) - Da formação inicial como ponto de partida à formação contínua como ponto de chegada, Ensino Superior e Formação de Professores, Universidade de Aveiro, Maio de 1985

FORMOSINHO, JOÃO (1986) - Qualro modelos ideais de formaçâa de Professores: o modelo empiricista, o modelo teoricista, o modelo compartimentado e o modelo integrado, Colóquio Luso-Francês sobre "As Ciências de Educação e Formação dos Professores», Instituto Franco-Português, Lisboa, Dezembro de 1986

FREITAS, C. VARELA (1983) - Estrutura de Formação de Professores - Módulo de Formaçäo para Professores, Boletim Informativo n 36 , Ministério da Educą̧ão, Maio de 1983

LOUREIRO, JOÃO EVANGELISTA (1983) - EVOlução das políticas de formação de professores do ensino secundário, in Revista da Universidade de Aveiro-Série Ciências da Educaçāo, II, noos 1 e 2.

\section{LEGISLAÇÃO REFERIDA}

\author{
Decreto-Lei 769-A/76, de 23 de Outubro \\ Portaria 679/77, de 8 de Novembro \\ Decreto-Lei 519/TI-79, de 29 de Dezembro \\ Portaria 970/80, de 12 de Novembro \\ Decretw-Lei 376i80, de 12 de Selembro \\ Portaria 64/81, de 16 de Janeiro \\ Decreto-Lei 211 - B/86, de 31 de Julho \\ Lei 46/86, de 14 de Outubro \\ Decreto-Lei 405/86, de 5 de Dezembro
}

\section{RESUMO}

O autor estuda, numa perspectiva de análise organizacional da educação, a evolução do papel dos órgãos de gestão pedagógica (C.P.) das escolas preparatórias e secundárias na formação de professores. As alterações dos regulamentos de funcionamento desses órgãos têm sido impostas pelas mudanças operadas pelos diversos modelos de formação, o que tem impossibilitado uma atitude coerente e estável dos C.P.s na formação contínua e no complemento de formação dos professores com habilitação académica incompleta.

A situação actual caracteriza-se pela ambiguidade, o que leva à consideração da necessidade de discernir claramente as responsabilidlades glubais de formação, da gestão dessa formação nas escolas, numa perspecliva de desenvolvimento escolar e comunitário. 


\begin{abstract}
The author studies the development of the role played by Portuguese preparatory and secondary schools pedagogic administration organs concerning teacher's training in a view of organized analysis.

The changes of those organs working rules have been imposed by the changes which have been done during the
\end{abstract}

different teacher's training patterns; this has prevented the C.P. to have a growing and stable position in the continous teacher's training and in the complementary training of teachers without a degree.

The present situation is characterized by ambiguity which takes us to consider the necessity of defining clearly the responsabilities of teacher's training and its organization at schools, in a vicw of school and university development. 